\title{
Association between miR-499 rs3746444 polymorphism and the risk of ischemic stroke: A systematic review and meta-analysis
}

\author{
XIANG-HONG LIU ${ }^{1}$, MEI-LING LIU ${ }^{2}$, RONG LIN ${ }^{1}$, YA-PING XING ${ }^{1}$, TING-LI ZHAO ${ }^{1}$, \\ WEN ZHANG ${ }^{1}$, MING ZHAO ${ }^{1}$, QING-RONG LIU $^{3}$ and KAI CAO ${ }^{4}$ \\ ${ }^{1}$ Department of Internal Medicine, JiZhong Energy XingTai MIG General Hospital, Xingtai, Hebei 054000; \\ ${ }^{2}$ Department of Prevention and Health Care, Dahongmen Community Healthcare Center, Beijing 100050; \\ ${ }^{3}$ School of Basic Medical Sciences, Shanxi Medical University, Taiyuan, Shanxi 030604; \\ ${ }^{4}$ Beijing Institute of Ophthalmology, Beijing Tongren Hospital, Capital Medical University, Beijing 100005, P.R. China
}

Received June 21, 2020; Accepted October 2, 2020

DOI: $10.3892 /$ wasj.2020.72

\begin{abstract}
The aim of the present study was to explore the generic association between the miR-499 (rs3746444) polymorphism and the risk of ischemic stroke (IS). A systematic review and meta-analysis was performed, and odds ratios (ORs) and 95\% confidence intervals (CIs) were used to quantitatively estimate the association. A total of 8 studies (involving 3,400 IS cases and 3,652 controls) were included in the present meta-analysis. The results of the allelic model ( $G$ allele vs. A allele) revealed a statistically significant association between the miR-499 (rs3746444) polymorphism and the risk of IS; the OR was 1.16 (95\% CI, 1.00-1.34; $\mathrm{P}<0.05)$. Similarly, the results of the recessive model (GG vs. AG + AA), the heterozygote model (AG vs. AA) and the homozygote model (GG vs. AA) were statistically significant; the ORs were 1.36 (95\% CI, 1.05-1.77; $\mathrm{P}<0.05), 1.11$ (95\% CI, 1.00-1.23; $\mathrm{P}<0.05)$ and 1.42 (95\% CI, 1.09-1.86; $\mathrm{P}<0.05)$, respectively. However, the dominant model (GG + AG vs. AA) did not exhibit any significant differences; the OR was 1.16 (95\% CI, 0.99-1.36; P>0.05). The results of the $\mathrm{Q}$ test indicated that the heterogeneity of the allelic model $\left(\mathrm{I}^{2}=63 \%, \mathrm{P}=0.01\right)$, as well as that of the dominant model $\left(\mathrm{I}^{2}=60 \%, \mathrm{P}=0.02\right)$, was relatively large. Subsequently, a sensitivity analysis was performed; the $\mathrm{I}^{2}$ of each model then decreased to $<50 \%$. Notably, by sensitivity analysis, both the allelic model and the dominant model exhibited a statistically significant association between the miR-499 (rs3746444) polymorphism and the risk of IS. Egger's test did not reveal any publication bias for any of the models. On the whole, the present study demonstrates that the miR-499 (rs3746444) polymorphism may contribute to an increased risk of IS.
\end{abstract}

Correspondence to: Dr Kai Cao, Beijing Institute of Ophthalmology, Beijing Tongren Hospital, Capital Medical University, 17 Hougou Alley, Dongcheng, Beijing 100005, P.R. China

E-mail: anzhen602@163.com

Key words: miRNAs, polymorphism, ischemic stroke, meta-analysis

\section{Introduction}

MicroRNAs (miRNAs or miRs) play important roles in gene regulation; more than half of human genes are known to be regulated by miRNAs. miRNAs are also involved in numerous pathological pathways/process, such as the inflammatory response $(1,2)$ and cancer development $(3,4)$, as well as in the formation/development of ischemic stroke (IS) (5-9).

Gene polymorphisms, including the Leu33Pro polymorphism (5), the apolipoprotein E gene polymorphism (among the Chinese population) (6,7), the Gly82Ser polymorphism (8) and the breast susceptibility gene 2 rs9534275 polymorphism (9), have been reported to be associated with an increased risk of IS. Several studies have assessed the association between the miR-499 (rs3746444) polymorphism and the risk of IS; however, the varying conclusions reached by the different studies are contradictory. Jeon et al (10) reported no difference in the allele frequencies of the miR-499 polymorphism between patients with IS and the controls; a previous meta-analysis (11) based on 3 studies reported a similar finding. On the contrary, Darabi et al (12) reported that the miR-499 A/G polymorphism was significantly associated with an increased risk of IS.

Thus, whether the miR-499 polymorphism increases the risk of IS remains controversial. The present study aimed to assess this association through a systematic review and meta-analysis. Odds ratios (ORs) and 95\% confidence intervals (CIs) were used to quantitatively estimate the association in 5 models, including the allelic model ( $\mathrm{G}$ allele vs. A allele), the dominant model ( $\mathrm{GG}+\mathrm{AG}$ vs. $\mathrm{AA})$, the recessive model (GG vs. AG + AA), the heterozygote model (AG vs. AA) and the homozygote model (GG vs. AA).

\section{Materials and methods}

Inclusion and exclusion criteria. Studies were selected under the following considerations: i) Studies should use a case-control design; ii) the subjects should include both patients with IS and healthy controls; iii) there must be extractable data on allele frequencies and genotype frequencies; iv) the subjects/models studied should be human, instead of animals or cells. 
Studies were excluded if any of the following conditions were met: i) Duplication studies; ii) case reports, letters, editorials, or reviews; iii) studies not written in the English language; iv) studies without extractable data on allele frequencies or genotype frequencies.

Databases and search strategy. A comprehensive literature search was performed using the PubMed, Embase, Science Direct and google scholar databases (from inception to June 15, 2020). The following terms were used to perform the literature search: rs3746444, miRNA-499, microRNA-499, miR-499; with a combination of stroke, ischemic, ischemia, ischemic stroke, cerebrovascular and cerebrovascular disease.

Data extraction. The data were extracted independently by 2 researchers using a predesigned data extraction form; the following information was extracted: i) Name of the first author; ii) year of publication; iii) country where the study was conducted; iv) the study design; v) sample size; vi) gene sequencing method; vii) P-values of Hardy-Weinberg equilibrium (HWE) of the control group. Most importantly, the frequencies of genotypes of the patients with IS and the controls were extracted.

Assessment of methodological quality. Two researchers used the Newcastle-Ottawa scale (13) to assess the quality of the included studies independently. For the Newcastle-Ottawa scale, a full score is 9; a score of 5-9 indicates a high methodological quality, whereas a score of 0-4 indicates poor quality. Any disagreement would be resolved by other authors following a comprehensive reassessment. Low-quality studies were excluded from the current meta-analysis.

Data synthesis and statistical analysis. Prior to the meta-analysis, the heterogeneity across studies was assessed by the $\mathrm{Q}$ test and the $\mathrm{I}^{2}$ statistic. $\mathrm{I}^{2}$ describes the percentage of variability caused by heterogeneity rather than by chance. An $\mathrm{I}^{2}<50 \%$ indicates a small heterogeneity; consequently a fixed-effects model would be used to perform the meta-analysis, otherwise a random-effects model would be used, and a sensitivity analysis (13) would be performed in the case of a large heterogeneity. Odds ratios (ORs) with $95 \%$ confidence intervals (CIs) were used to estimate the association between the miR-499 (rs3746444) polymorphism and the risk of IS. Egger's test (14) was used to determine whether there was a publication bias. The significance level was set as 0.05, two-tailed. All the analyses were performed using the open source $\mathrm{R}$ program (version 4.0.1).

\section{Results}

Study selection. A total of 187 studies were identified through initial database searching. A total of 65 duplicates were removed, and 122 records were reviewed for title and Abstract. In total, 103 irrelevant records and studies not written in the English language were further excluded. A total of 19 articles were full-text reviewed, and 11 records were further excluded due to ineligible study design or the lack of extractable data. The details of the study selection process are presented in Fig. 1.

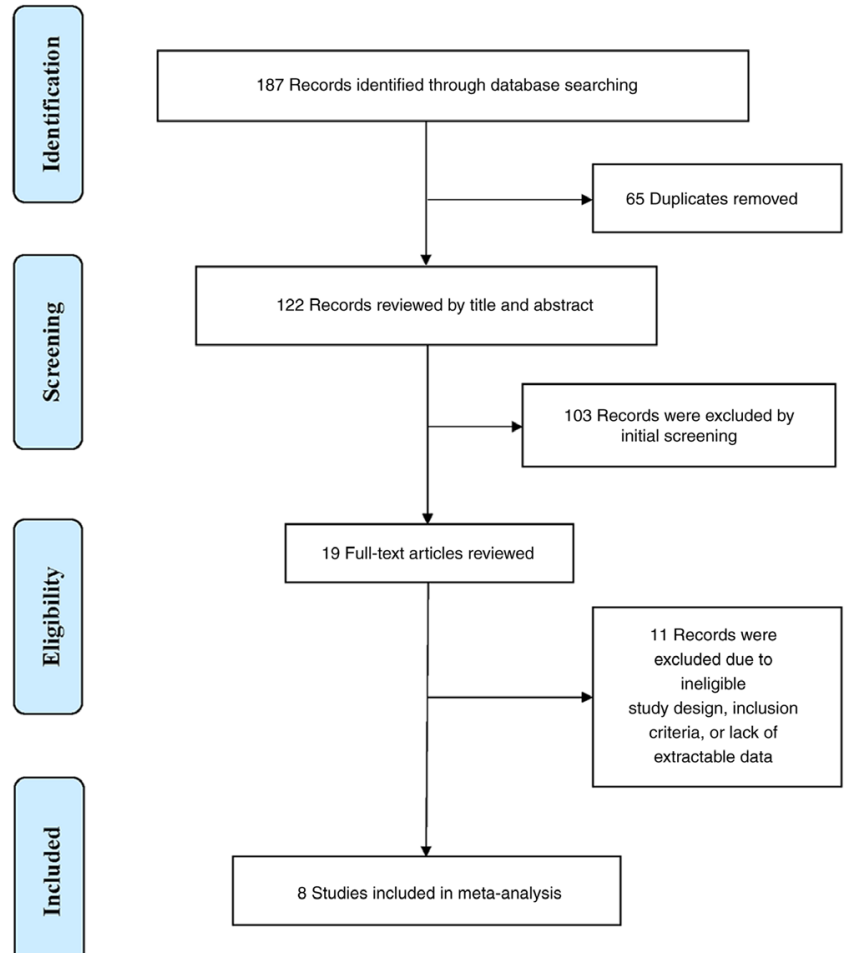

Figure 1. Flow chart of the study selection.

Characteristics of included studies. A total of 8 studies $(10,12,15-20)$, involving 3,400 patients with IS and 3,652 controls, met the inclusion and exclusion criteria. The characteristics of the included studies are presented in Table I. A total of 5 studies were carried out in China, 2 in Korea and one in Iran. All studies were hospital-based studies, and used a case-control study design. Polymerase chain reaction-restriction fragment length polymorphism (PCR-RFLP) was the most popular method for genotype sequencing. The age and sex of the patients in the selected studies were matched between the patients with IS and the controls in each study. Only in 1 study, the P-value of HWE was $<0.05$.

Study quality assessment. The mean Newcastle-Ottawa score of the included studies was 7 (Table II); thus, the overall quality of the included studies was high.

Results of the allelic model. The results of the allelic model revealed a statistically significant association between the miR-499 (rs3746444) polymorphism and an increased risk of IS (Fig. 2); the OR was 1.16 (95\% CI, 1.00-1.34). However, the $\mathrm{I}^{2}$ was $63 \%$, and there was a large heterogeneity across the included studies. A sensitivity analysis was further performed. It was found that after omitting the study of Zhu et al, 2020 (20), the $\mathrm{I}^{2}$ decreased to $51.3 \%$ (data not shown). Moreover, the conclusion remained unaltered; the association between the miR-499 (rs3746444) polymorphism and the increased risk of IS was still significant; the OR was 1.19 (95\% CI, 1.08-1.31; $\mathrm{P}<0.05$ ) (data not shown).

Results of the dominant model. The results of the dominant model revealed a non-significant association between the miR-499 (rs3746444) polymorphism and the risk of IS (Fig. 3); 
Table I. Characteristics of the included studies.

\begin{tabular}{|c|c|c|c|c|c|c|c|c|}
\hline \multirow[b]{2}{*}{ Author } & \multirow[b]{2}{*}{ Year } & \multirow[b]{2}{*}{ Country } & \multirow[b]{2}{*}{ Study design } & \multicolumn{2}{|c|}{ Sample size } & \multirow[b]{2}{*}{ Genotyping methods } & \multirow[b]{2}{*}{ P-value (HWE) } & \multirow[b]{2}{*}{ (Refs.) } \\
\hline & & & & Cases & Controls & & & \\
\hline Jeon et al & 2013 & Korea & Hospital-based & 678 & 553 & PCR-RFLP & 0.740 & $(10)$ \\
\hline Liu et al & 2014 & China & Hospital-based & 296 & 391 & PCR-RFLP & 0.394 & (16) \\
\hline Huang et al & 2015 & China & Hospital-based & 531 & 531 & TaqMan & 0.002 & (15) \\
\hline Luo et al & 2017 & China & Hospital-based & 298 & 303 & RT-PCR & 0.447 & (17) \\
\hline Darabi et al & 2019 & Iran & Hospital-based & 470 & 489 & PCR-RFLP & 0.061 & (12) \\
\hline Zhu et al & 2018 & China & Hospital-based & 296 & 378 & PCR-RFLP & 0.512 & $(18)$ \\
\hline Hong et al & 2019 & Korea & Hospital-based & 264 & 455 & PCR & 0.999 & (19) \\
\hline Zhu et al & 2020 & China & Hospital-based & 567 & 552 & PCR-LDR & 0.630 & $(20)$ \\
\hline
\end{tabular}

PCR, polymerase chain reaction; PCR-RFLP, PCR-restriction fragment length polymorphism; polymerase chain reaction-ligation detection reaction.

\begin{tabular}{|c|c|c|c|c|c|c|c|c|c|}
\hline Study & Events & $\begin{array}{l}\text { Case } \\
\text { total }\end{array}$ & Events & $\begin{array}{r}\text { ontrol } \\
\text { total }\end{array}$ & Odds ratio & OR & $95 \%-\mathrm{Cl}$ & $\begin{array}{l}\text { Weight } \\
\text { (fixed) }\end{array}$ & $\begin{array}{c}\text { Weight } \\
\text { (random) }\end{array}$ \\
\hline Jeon et al, 2013 (10) & 241 & 1356 & 206 & 1106 & 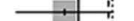 & 0.94 & {$[0.77 ; 1.16]$} & $19.7 \%$ & $14.4 \%$ \\
\hline Liu et al, 2014 (16) & 134 & 592 & 127 & 782 & & 1.51 & {$[1.15 ; 1.98]$} & $8.9 \%$ & $11.9 \%$ \\
\hline Huang et al, 2015 (15) & 133 & 1062 & 128 & 1062 & + & 1.04 & {$[0.81 ; 1.35]$} & $11.8 \%$ & $12.3 \%$ \\
\hline Luo et al, 2017 (17) & 88 & 596 & 65 & 606 & & 1.44 & {$[1.02 ; 2.03]$} & $5.8 \%$ & $9.5 \%$ \\
\hline Darabi et al, 2018 (12) & 263 & 940 & 218 & 978 & & 1.35 & {$[1.10 ; 1.67]$} & $16.2 \%$ & $14.3 \%$ \\
\hline Zhu et al, 2018 (18) & 159 & 792 & 142 & 756 & 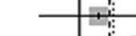 & 1.09 & {$[0.84 ; 1.40]$} & $12.2 \%$ & $12.6 \%$ \\
\hline Hong et al, 2019 (19) & 104 & 526 & 146 & 910 & & 1.29 & {$[0.98 ; 1.70]$} & $9.0 \%$ & $11.6 \%$ \\
\hline Zhu et al, 2020 (20) & 162 & 1134 & 179 & 1104 & \pm & 0.86 & {$[0.68 ; 1.08]$} & $16.4 \%$ & $13.4 \%$ \\
\hline \multirow{3}{*}{$\begin{array}{l}\text { Fixed effect model } \\
\text { Random effects model } \\
\text { Heterogeneity: } I^{2}=63 \%, \tau\end{array}$} & & 6998 & & 7304 & 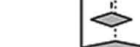 & \multirow{3}{*}{$\begin{array}{l}1.14 \\
1.16\end{array}$} & \multirow{3}{*}{$\begin{array}{l}{[1.04 ; 1.24]} \\
{[1.00 ; 1.34]}\end{array}$} & \multirow{2}{*}{$\begin{array}{r}100.0 \% \\
--\end{array}$} & \multirow{3}{*}{$100.0 \%$} \\
\hline & & & & & $<$ & & & & \\
\hline & & & & & 1 & & & & \\
\hline
\end{tabular}

Figure 2. Forest plot of the allelic model.

\begin{tabular}{|c|c|c|c|c|c|c|c|c|c|}
\hline Study & Events & $\begin{array}{l}\text { Case } \\
\text { total }\end{array}$ & Events & $\begin{array}{r}\text { Control } \\
\text { total }\end{array}$ & Odds ratio & OR & $95 \%-\mathrm{Cl}$ & $\begin{array}{r}\text { Weight } \\
\text { (fixed) }\end{array}$ & $\begin{array}{r}\text { Weight } \\
\text { (random) }\end{array}$ \\
\hline Jeon et al, 2013 (10) & 218 & 678 & 188 & 553 & +1 & 0.92 & {$[0.72 ; 1.17]$} & $19.8 \%$ & $14.5 \%$ \\
\hline Liu et al, 2014 (16) & 115 & 296 & 113 & 391 & & 1.56 & {$[1.13 ; 2.15]$} & $8.4 \%$ & $11.6 \%$ \\
\hline Huang et al, 2015 (15) & 133 & 531 & 128 & 531 & & 1.05 & {$[0.80 ; 1.39]$} & $13.5 \%$ & $13.0 \%$ \\
\hline Luo et al, 2017 (17) & 83 & 298 & 59 & 303 & & 1.60 & {$[1.09 ; 2.34]$} & $6.0 \%$ & $9.7 \%$ \\
\hline Darabi et al, $2018(12)$ & 218 & 470 & 188 & 489 & $T$ & 1.39 & {$[1.07 ; 1.79]$} & $13.9 \%$ & $13.8 \%$ \\
\hline Zhu et al, $2018(18)$ & 141 & 396 & 129 & 378 & + & 1.07 & {$[0.79 ; 1.43]$} & $12.0 \%$ & $12.4 \%$ \\
\hline Hong et al, 2019 (19) & 90 & 263 & 134 & 455 & & 1.25 & {$[0.90 ; 1.72]$} & $9.1 \%$ & $11.4 \%$ \\
\hline Zhu et al, 2020 (20) & 153 & 567 & 166 & 552 & + & 0.86 & {$[0.66 ; 1.11]$} & $17.3 \%$ & $13.7 \%$ \\
\hline Fixed effect model & & 3499 & & 3652 & $<$ & 1.13 & {$[1.02 ; 1.25]$} & $100.0 \%$ & \\
\hline \multirow{2}{*}{\multicolumn{5}{|c|}{$\begin{array}{l}\text { Random effects model } \\
\text { Heterogeneity: } I^{2}=60 \%, \tau^{2}=0.0319, p=0.02\end{array}$}} & & & & 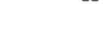 & \\
\hline & & & & & 1 & & & & \\
\hline
\end{tabular}

Figure 3. Forest plot of the dominant model.

the OR was 1.16 (95\% CI, 0.99-1.36). The $\mathrm{I}^{2}$ was $60 \%$; a sensitivity analysis was subsequently performed. After omitting the study of Zhu et al, 2020 (20), the $\mathrm{I}^{2}$ dropped to $50.9 \%$ (data not shown). Notably, the conclusion changed, and there was a statistically significant association between the miR-499 (rs3746444) polymorphism and the risk of IS; the OR was 1.19 (95\% CI, 1.07-1.33) (data not shown).

Results of the recessive model. The results of the recessive model (Fig. 4) revealed a statistically significant association between the miR-499 (rs3746444) polymorphism and the increased risk of IS; the OR was 1.36 (95\% CI, 1.05-1.77). The heterogeneity was small $\left(\mathrm{I}^{2}=4 \%\right)$.

Results of the heterozygote model. The results of the heterozygote model (Fig. 5) also revealed a statistically significant association between the miR-499 (rs3746444) polymorphism and the increased risk of IS; the OR was 1.11 (95\% CI, 1.00-1.23). The $\mathrm{I}^{2}$ was $50 \%$; the heterogeneity was not large.

Results of the homozygote model. The results of the homozygote model (Fig. 6) revealed a statistically significant 


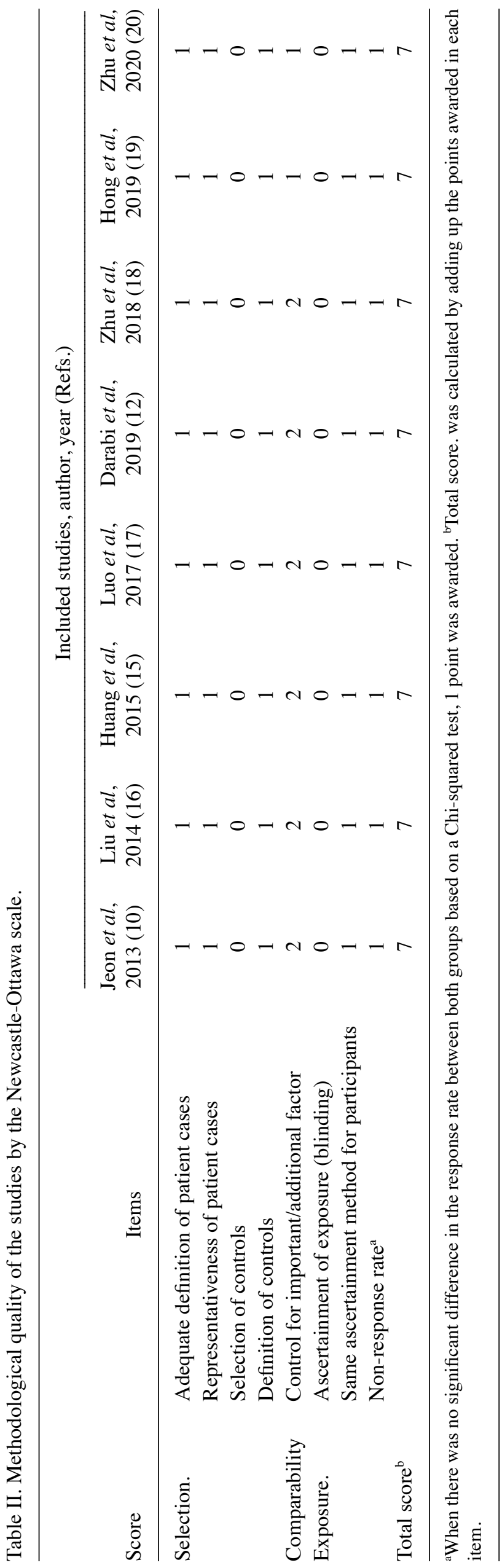

Table III. Egger's test results.

\begin{tabular}{lrc}
\hline Model & $\mathrm{t}$ value & P-value \\
\hline Allele & 0.818 & 0.440 \\
Dominant & 2.223 & 0.067 \\
Recessive & -0.969 & 0.377 \\
Heterozygous & 2.124 & 0.053 \\
Homozygous & -0.898 & 0.410 \\
\hline
\end{tabular}

association between the miR-499 (rs3746444) polymorphism and the increased risk of IS; the OR was $1.42(95 \% \mathrm{CI}$, 1.09-1.86). The heterogeneity was small $\left(\mathrm{I}^{2}=23 \%\right)$.

Publication bias. There was no publication bias for all the 5 models according to results of Eggers' test (Table III).

\section{Discussion}

The present meta-analysis aimed to determine whether the miR-499 (rs3746444) polymorphism had an influence on the risk of IS based on case-control studies. The main finding was that the miR-499 (rs3746444) polymorphism was associated with an increased risk of IS; the association was statistically significant in the allelic model, the recessive model, the heterozygote model and the homozygote model. Furthermore, by sensitivity analysis, the dominant model was found to be significant.

In a previous review article, Zou et al (21) concluded that the miR-499 (rs3746444) polymorphism may not be associated with a risk of IS in Asian populations. However, in the present study, neither the allelic model, dominant model, recessive model, homozygote model, or the heterozygote model were found to be significant in the study by Zou et al. However, as 3 Chinese articles were included in the review article by Zou et al (21), it is difficult for researchers who do not speak Chinese to repeat the results.

The present study attempted to explain why findings by the previous review article were contrary to those of the present study. Considering that the previous review article focused on a Chinese population, the present study performed a subgroup analysis in the meta-analysis, and studies were divided by ethnicity into subgroup 1 (studies based on Chinese population) and subgroup 2 (studies based on non-Chinese population). Subgroup analysis revealed that the homozygote model and the recessive model of subgroup 1 was indeed non-significant; however, the allelic model, the dominant model, and the heterozygote model still exhibited a significant association between the miR-499 (rs3746444) polymorphisms and the increased risk of IS. Notably, there was a tendency that the ORs of subgroup 2 were larger than those of subgroup 1. The results of subgroup analysis indicated that the association between the miR-499 (rs3746444) polymorphism and the risk of IS may vary for different ethnicities (data not shown). The relatively small sample size of the study by Zou et al (21) (there were only 4 studies if the 3 articles written in Chinese were not counted) may be another reason why non-significant results were found, and that is why an updated meta-analysis is of utmost importance. 


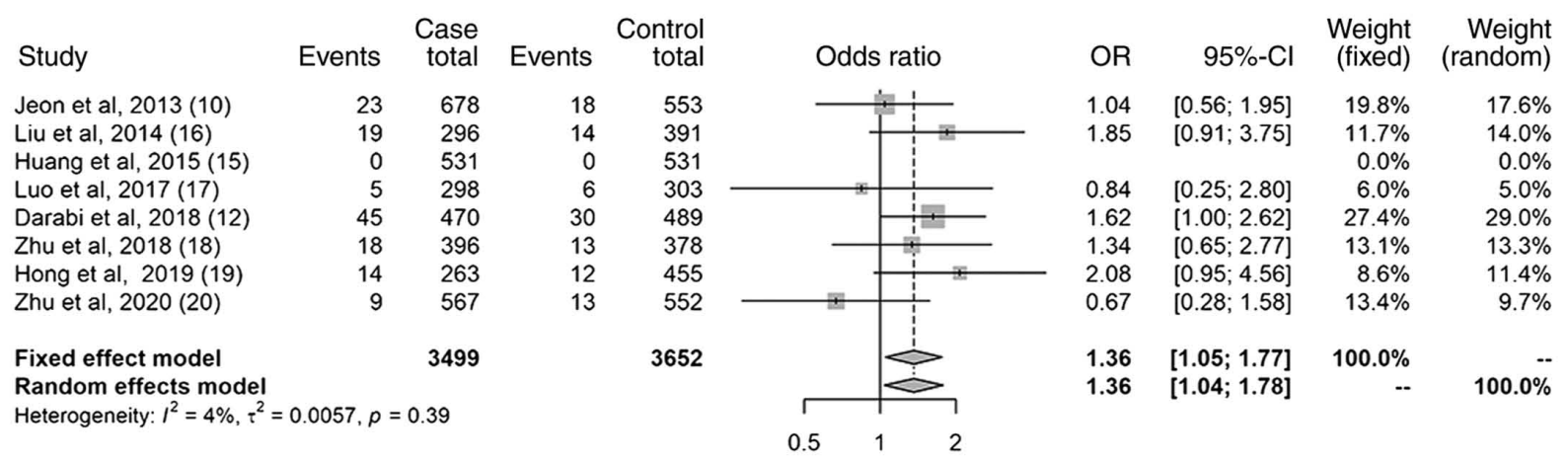

Figure 4. Forest plot of the recessive model.

\begin{tabular}{|c|c|c|c|c|c|c|c|c|c|}
\hline Study & Events & $\begin{array}{c}\text { Case } \\
\text { total }\end{array}$ & Events & $\begin{array}{r}\text { Control } \\
\text { total }\end{array}$ & Odds ratio & OR & $95 \%-\mathrm{Cl}$ & $\begin{array}{r}\text { Weight } \\
\text { (fixed) }\end{array}$ & $\begin{array}{r}\text { Weight } \\
\text { (random) }\end{array}$ \\
\hline Jeon et al, $2013(10)$ & 195 & 655 & 170 & 535 & 9 & 0.91 & {$[0.71 ; 1.17]$} & $19.7 \%$ & $15.0 \%$ \\
\hline Liu et al, 2014 (16) & 96 & 277 & 99 & 377 & & 1.49 & {$[1.06 ; 2.09]$} & $8.2 \%$ & $11.1 \%$ \\
\hline Huang et al, 2015 (15) & 133 & 531 & 128 & 531 & 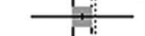 & 1.05 & {$[0.80 ; 1.39]$} & $14.4 \%$ & $13.5 \%$ \\
\hline Luo et al, 2017 (17) & 78 & 293 & 53 & 297 & & 1.67 & {$[1.13 ; 2.48]$} & $5.8 \%$ & $9.3 \%$ \\
\hline Darabi et al, 2018 (12) & 173 & 425 & 158 & 459 & & 1.31 & {$[1.00 ; 1.72]$} & $13.5 \%$ & $13.8 \%$ \\
\hline Zhu et al, $2018(18)$ & 123 & 378 & 116 & 365 & 4 & 1.04 & {$[0.76 ; 1.41]$} & $11.9 \%$ & $12.3 \%$ \\
\hline Hong et al, 2019 (19) & 76 & 249 & 122 & 443 & & 1.16 & {$[0.82 ; 1.63]$} & $9.1 \%$ & $11.0 \%$ \\
\hline Zhu et al, $2020(20)$ & 144 & 558 & 153 & 539 & 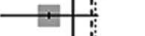 & 0.88 & {$[0.67 ; 1.15]$} & $17.3 \%$ & $14.1 \%$ \\
\hline \multirow{3}{*}{$\begin{array}{l}\text { Fixed effect model } \\
\text { Random effects model } \\
\text { Heterogeneity: } I^{2}=50 \%, \tau^{2}\end{array}$} & & 3366 & & 3546 & & 1.11 & {$[1.00 ; 1.23]$} & $100.0 \%$ & -- \\
\hline & & & & & & 1.13 & {$[0.97 ; 1.32]$} & -. & $100.0 \%$ \\
\hline & & & & & & & & & \\
\hline
\end{tabular}

Figure 5. Forest plot of the heterozygote model.

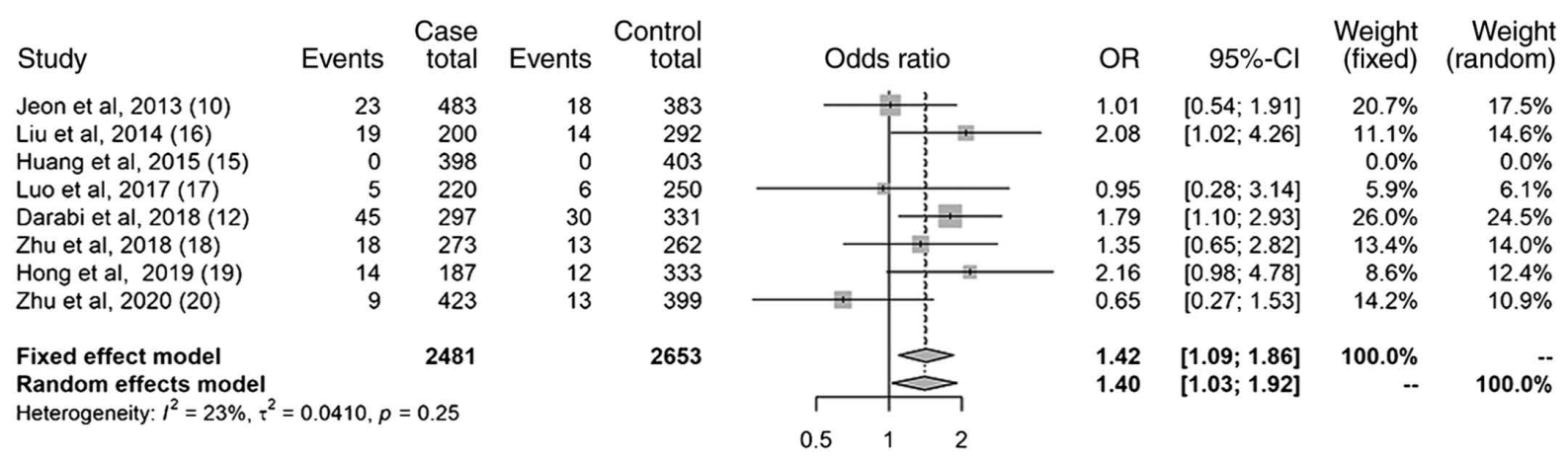

Figure 6. Forest plot of the homozygote model.

The association between the miR-499 polymorphism and the increased risk of IS was understandable: It has been reported that hsa-miR-499 plays a role in cell apoptosis under ischemic conditions (22); the mechanisms involved may be that miR-499 inhibits cell apoptosis by suppressing the dephosphorylation of dynamin-related protein-1 (Drpl) that is mediated by calcineurin. miR-499 affects the regulation of C-reactive protein (CRP) (23), and C-reactive protein has been reported to be a cause of cerebral ischemia (24). Similarly, TNF- $\alpha$ (25), another general cause of cerebral ischemia, has been reported to be regulated by miR-499; both CRP and TNF- $\alpha$ are activated under conditions of stress (26). Furthermore, it has been reported that the thrombosis and inflammation pathways of the.

In conclusion, miR-circulation system can be influenced by the miR-499 (rs3746444) polymorphism; an A:U pair to a G:U mismatch of hsa-miR-499 precursor caused by miR-499 (rs3746444) $(27,28)$ polymorphism can alter the function/expression of mature hsa-miR-499, and the regulation of its' target mRNAs. The miR-499 polymorphism is associated with a risk of IS, and the G allele increases the risk of IS.

There are two limitations to the current meta-analysis. On the one hand, all the included studies used a case-control design; there may thus be a selection bias, which could enhance or weaken the true association between miR-499 polymorphism and the risk of IS. On the other hand, subgroup analysis based on 8 studies was not sufficient; thus, whether the association between the miR-499 polymorphism and risk of IS is dependent on ethnicity remains a matter of debate.

\section{Acknowledgements}

Not applicable. 


\section{Funding}

Not applicable.

\section{Availability of data and materials}

The datasets used and/or analyzed during the current study is available from the corresponding author on reasonable request.

\section{Authors' contributions}

KC designed the study. XHL and MLL performed the literature search and manuscript writing. RL extracted the data for the analysis. YPX performed the quality control of the extracted data. MZ and QRL performed the data analysis. WZ and TLZ interpreted the data and revised the manuscript. All authors read and approved the final manuscript.

\section{Ethics approval and consent to participate}

Not applicable.

\section{Patient consent for publication}

Not applicable.

\section{Competing interests}

The authors declare that they have no competing interests.

\section{References}

1. Olivieri F, Capri M, Bonafe M, Morsiani C, Jung HJ Spazzafumo L, Vina J and Suh Y: Circulating miRNAs and miRNA shuttles as biomarkers: Perspective trajectories of healthy and unhealthy aging. Mech Ageing Dev 165: 162-170, 2017.

2. Xu XM and Zhang HJ: MiRNAs as new molecular insights into inflammatory bowel disease: Crucial regulators in autoimmunity and inflammation. World J Gastroenterol 22: 2206-2218, 2016.

3. Qadir MI and Faheem A: MiRNA: A diagnostic and therapeutic tool for pancreatic cancer. Crit Rev Eukaryot Gene Expr 27: 197-204, 2017.

4. Huang Z, Zhu D, Wu L, He M, Zhou X, Zhang L, Zhang H, Wang W, Zhu J, Cheng W, et al: Six serum-based miRNAs as potential diagnostic biomarkers for gastric cancer. Cancer Epidemiol Biomarkers Prev 26: 188-196, 2017.

5. Kekomaki S, Hamalainen L, Kauppinen-Makelin R, Palomaki H, Kaste M and Kontula K: Genetic polymorphism of platelet glycoprotein IIIa in patients with acute myocardial infarction and acute ischaemic stroke. J Cardiovasc Risk 6: 13-17, 1999.

6. Gu L, Su L, Chen Q, Liang B, Qin Y, Xie J, Wu G, Yan Y, Long J, $\mathrm{Wu} \mathrm{H}$, et al: Association between the apolipoprotein $\mathrm{E}$ gene polymorphism and ischemic stroke in Chinese populations: New data and meta-analysis. Exp Ther Med 5: 853-859, 2013.

7. Ariyaratnam R, Casas JP, Whittaker J, Smeeth L, Hingorani AD and Sharma P: Genetics of ischaemic stroke among persons of non-European descent: A meta-analysis of eight genes involving approximately 32,500 individuals. PLoS Med 4: e131, 2007.

8. Ma WQ, Qu QR, Zhao Y and Liu NF: Association of RAGE gene Gly82Ser polymorphism with coronary artery disease and ischemic stroke: A systematic review and meta-analysis. Medicine (Baltimore) 95: e5593, 2016.

9. Miao L, Yin RX, Yang S, Huang F, Chen WX and Cao XL: Association between single nucleotide polymorphism rs9534275 and the risk of coronary artery disease and ischemic stroke. Lipids Health Dis 16: 193, 2017.
10. Jeon YJ, Kim OJ, Kim SY, Oh SH, Oh D, Kim OJ, Shin BS and Kim NK: Association of the miR-146a, miR-149, miR-196a2, and miR-499 polymorphisms with ischemic stroke and silent brain infarction risk. Arterioscler Thromb Vasc Biol 33: 420-430, 2013.

11. Xiao Y, Bao MH, Luo HQ, Xiang J and Li JM: A meta-analysis of the association between polymorphisms in MicroRNAs and risk of ischemic stroke. Genes (Basel) 6: 1283-1299, 2015.

12. Darabi H, Salmaninejad A, Jaripour ME, Azarpazhooh MR, Mojarrad M and Sadr-Nabavi A: Association of the genetic polymorphisms in immunoinflammatory microRNAs with risk of ischemic stroke and subtypes in an Iranian population. J Cell Physiol 234: 3874-3886, 2019.

13. Wells GA, Shea B, O'Connell D, Peterson J, Welch V, Losos M and Tugwell P: The Newcastle-Ottawa Scale (NOS) for assessing the quality of nonrandomised studies in meta-analyses. The Ottawa Hospital Research Institute. http://www.ohri.ca/programs/ clinical_epidemiology/oxford.asp.

14. Egger $\bar{M}$, Davey Smith G, Schneider $M$ and Minder C: Bias in meta-analysis detected by a simple, graphical test. BMJ 315: 629-634, 1997.

15. Huang S, Zhou S, Zhang Y, Lv Z, Li S, Xie C, Ke Y, Deng P, Geng Y, Zhang Q, et al: Association of the genetic polymorphisms in pre-microRNAs with risk of ischemic stroke in a Chinese population. PLoS One 10: e117007, 2015.

16. Liu Y, Ma Y, Zhang B, Wang SX, Wang XM and Yu JM: Genetic polymorphisms in pre-microRNAs and risk of ischemic stroke in a Chinese population. J Mol Neurosci 52: 473-480, 2014.

17. Luo HC, Luo QS, Wang CF, Lei M, Li BL and Wei YS: Association of miR-146a, miR-149, miR-196a2, miR-499 gene polymorphisms with ischemic stroke in a Chinese people. Oncotarget 8: 81295-81304, 2017.

18. Zhu X, Hou R, Ma A, Yang S and Pan X: Associations of miR-146a, miR-149, miR-196a2, and miR-499 polymorphisms with ischemic stroke in the Northern Chinese Han population. Med Sci Monit 24: 7366-7374, 2018

19. Hong SJ, Kim SK, Yun DH, Chon J and Park HJ: Association between MicroRNA-4669 polymorphism and ischemic stroke in a Korean population. Dis Markers 2019: 7238319, 2019.

20. Zhu R, Wang QW, Zhao J, Liu X and He Z: MiR-149 and miR-499 gene polymorphism and the incident of ischemic stroke in the Asian population: From a case-control study to meta-analysis. Clin Neurol Neurosurg 193: 105789, 2020.

21. Zou D, Liu C, Zhang Q, Li X, Qin G, Huang Q, Meng Y, Chen L and Wei J: Association between polymorphisms in microRNAs and ischemic stroke in an Asian population: Evidence based on 6,083 cases and 7,248 controls. Clin Interv Aging 13: 1709-1726, 2018.

22. Wang JX, Jiao JQ, Li Q, Long B, Wang K, Liu JP, Li YR and Li PF: MiR-499 regulates mitochondrial dynamics by targeting calcineurin and dynamin-related protein-1. Nat Med 17: 71-78, 2011.

23. Yang B, Chen J, Li Y, Zhang J, Li D, Huang Z, Cai B, Li L, Shi Y, Ying B and Wang L: Association of polymorphisms in pre-miRNA with inflammatory biomarkers in rheumatoid arthritis in the Chinese Han population. Hum Immunol 73: 101-106, 2012.

24. Cattin L, Da Col PG, Feruglio FS, Finazzo L, Rimondi S, Descovich G, Manzato E, Zambon S, Crepaldi G, Siepi D, et al: Efficacy of ciprofibrate in primary type II and IV hyperlipidemia: The Italian multicenter study. Clin Ther 12: 482-488, 1990.

25. El Gazzar M, Church A, Liu T and McCall CE: MicroRNA-146a regulates both transcription silencing and translation disruption of TNF- $\alpha$ during TLR4-induced gene reprogramming. J Leukoc Biol 90: 509-519, 2011.

26. Calcagni E and Elenkov I: Stress system activity, innate and T helper cytokines, and susceptibility to immune-related diseases. Ann N Y Acad Sci 1069: 62-76, 2006.

27. Hu Z, Liang J, Wang Z, Tian T, Zhou X, Chen J, Miao R, Wang Y, Wang $X$ and Shen $H$ : Common genetic variants in pre-microRNAs were associated with increased risk of breast cancer in Chinese women. Hum Mutat 30: 79-84, 2009.

28. Xiang Y, Fan S, Cao J, Huang S and Zhang LP: Association of the microRNA-499 variants with susceptibility to hepatocellular carcinoma in a Chinese population. Mol Biol Rep 39: 7019-7023, 2012.

This work is licensed under a Creative Commons Attribution-NonCommercial-NoDerivatives 4.0 International (CC BY-NC-ND 4.0) License. 